\title{
Long-acting insulin
}

National Diabetes Information Clearinghouse (NDIC)

\section{Definitions}

Insulin

Defined by National Diabetes Information Clearinghouse (NDIC)

Onset

Defined by National Diabetes Information Clearinghouse (NDIC)

Peak

Defined by National Diabetes Information Clearinghouse (NDIC)

Duration

Defined by National Diabetes Information Clearinghouse (NDIC)

Insulin detemir

Defined by National Diabetes Information Clearinghouse (NDIC)

Insulin glargine

Defined by National Diabetes Information Clearinghouse (NDIC)

\section{Source}

National Diabetes Information Clearinghouse (U.S.). (2009). The diabetes dictionary. [Bethesda, Md.]: U.S. Dept. of Health and Human Services, National Institutes of Health, National Institute of Diabetes and Digestive and Kidney Diseases, National Diabetes Information Clearinghouse.

A type of insulin with an onset of 1 hour, no peak, and a duration of 20 to 26 hours. See insulin detemir and insulin glargine. 